EXTENDED REPORT

\title{
Vitrectomy and gas tamponade without internal limiting membrane peeling for myopic foveoschisis
}

\author{
A K H Kwok, T Y Y Lai, W W K Yip
}

Br J Ophthalmol 2005;89:1180-1183. doi: 10.1136/bjo.2005.069427

See end of article for authors' affiliations

....................

Correspondence to: Dr T Y Y Lai, Department of Ophthalmology and Visual Sciences, The Chinese University of Hong Kong, Hong Kong Eye Hospital, 147K Argyle Street, Kowloon, Hong Kong; tyylai@netvigator.com

Accepted for publication 1 May 2005

\begin{abstract}
Aim: To evaluate the clinical and anatomical outcomes of pars plana vitrectomy and gas tamponade without internal limiting membrane (ILM) peeling in symptomatic patients caused by myopic foveoschisis. Methods: Nine eyes in eight highly myopic patients who had myopic foveoschisis with foveal detachment underwent vitrectomy without ILM peeling followed by gas tamponade. Main outcome measures include change in best corrected visual acuity (BCVA) and changes in height of the foveal detachment and resolution of the myopic foveoschisis measured by optical coherence tomography (OCT).

Results: After surgery, BCVA improved in eight eyes with the median BCVA improved from $20 / 80$ to $20 / 50(p=0.012$ ). The mean line of visual improvement was 3.6 lines. OCT showed complete resolution of myopic foveoschisis with complete foveal reattachment in seven (77.8\%) eyes with partial resolution in two $(22.2 \%)$ eyes. The mean height of foveal detachment decreased from $505 \mu \mathrm{m}$ preoperatively to $21 \mu \mathrm{m}$ postoperatively $(\mathrm{p}<0.001)$.

Conclusions: Vitrectomy without ILM peeling followed by gas tamponade appeared to result in favourable visual and anatomical outcomes for treating myopic foveoschisis in highly myopic eyes. The results are comparable with studies in which ILM removal was performed. Further controlled study will be useful to determine the role of ILM peeling in these patients.
\end{abstract}

$M$ acular retinoschisis with foveal detachment is a condition that occasionally occurs in highly myopic eyes with posterior staphyloma and is also known as myopic foveoschisis. ${ }^{12}$ With the use of optical coherence tomography (OCT), it has been estimated that the prevalence of macular retinoschisis in highly myopic eyes with posterior staphyloma ranged from $9 \%$ to as high as $34 \% .^{3-5}$ Although the exact pathogenesis is uncertain, it has been postulated that myopic foveoschisis is a result of vitreous traction and may have a role in the formation of myopic macular hole. ${ }^{156}$

Patients with myopic foveoschisis have variable severity of visual impairment and they may be asymptomatic due to the underlying myopic chorioretinal degeneration. In symptomatic patients with reduced vision or central metamorphopsia, pars plana vitrectomy with internal limiting membrane (ILM) peeling and gas tamponade have been shown to result in the resolution of myopic foveoschisis with visual improvement. $^{27-9}$ The rationale of ILM peeling is to remove the macular traction that might have caused the myopic foveoschisis and the associated retinal detachment. ${ }^{10}$ This is similar to the basis of ILM peeling in idiopathic and myopic macular holes for improving macular hole closure rates. ${ }^{11-13}$ ILM peeling may also remove collagen fibres and cell debris which are frequently observed in the inner surface of ILM removed from patients with myopic foveoschisis. ${ }^{14}$

Despite evidence suggesting that vitrectomy with ILM peeling is beneficial for the treatment of myopic foveoschisis, it remained unclear whether ILM peeling is essential in treating myopic foveoschisis. ${ }^{2}$ ILM peeling is technically challenging due to its transparency and friability. In highly myopic eyes, ILM removal is even more difficult as the ILM in highly myopic eyes seems to be thinner and tends to fragment into pieces during its removal. ${ }^{13}$ The use of dye staining like indocyanine green or trypan blue has improved the visualisation of ILM for removal but potential retinal toxicities have been demonstrated in both laboratory and clinical studies. ${ }^{15-18}$ Therefore, it will be of interest to determine whether vitrectomy without ILM peeling will be sufficient in treating myopic foveoschisis. The purpose of this prospective study is to evaluate the outcomes of vitrectomy and gas tamponade without ILM peeling for the treatment of highly myopic patients with symptomatic visual impairment as a result of myopic foveoschisis.

\section{PATIENTS AND METHODS}

\section{Patient selection}

Consecutive patients with visual loss or central metamorphopsia caused by myopic foveoschisis scheduled for vitrectomy and gas tamponade at Hong Kong Sanatorium and Hospital and Hong Kong Eye Hospital were prospectively recruited from May 2002 to July 2004. Exclusion criteria included patients aged less than 18 years, patients with myopia of less than -6 diopters (D), and the presence of macular hole documented on OCT. Informed consent was obtained from all patients.

\section{Data collection}

Preoperative data recorded include patients' demographics, duration of symptoms, lens status, and the best corrected visual acuity (BCVA). Preoperative and postoperative BCVA were measured by certified optometrists with a standard Snellen chart. Snellen BCVA was converted to logarithm of the minimum angle of resolution (logMAR) BCVA for analysis. Each 0.1 logMAR unit represents one line of Snellen visual acuity. ${ }^{19}$ Intraoperative data collected include the presence or absence of posterior vitreous detachment and preretinal membrane. All intraoperative complications were also recorded. Preoperative and postoperative OCT recordings were performed using an OCT 2 machine (Humphrey Instruments, San Leandro, CA, USA) in the first four patients and an OCT 3 machine (Stratus OCT, Carl Zeiss Meditec Inc, Dublin, CA, USA) in the last four patients when the newer

Abbreviations: BCVA, best corrected visual acuity; ILM, internal limiting membrane; IOL, intraocular lens; OCT, optical coherence tomography; PVD, posterior vitreous detachment. 
version became available. Both vertical and horizontal scans of $3.0 \mathrm{~mm}$ to $6.0 \mathrm{~mm}$ in length were recorded. The height of foveal detachment was measured using the retinal thickness mode in the OCT software and is defined as the distance between the inner surface of the retinal pigment epithelium and the outer surface of the neurosensory retina at the fovea. ${ }^{2}$

\section{Surgical techniques}

All patients underwent standard subtotal three port pars plana vitrectomy. Phacoemulsification with implantation of intraocular lens was performed before vitrectomy in some patients to prevent further cataract development. Confirmation of the presence of posterior vitreous detachment (PVD) was routinely performed by using active aspiration. Any visible epiretinal membrane was gently removed using an intraocular forceps to avoid formation of iatrogenic macular or retinal hole. A microvitreoretinal (MVR) blade was also used to gently scratch the macula to engage any indistinct vitreous sheet that was removed. No ILM peeling was attempted. Two stage fluid/air exchange was then performed followed by injection of $12 \%$ perfluoropropane $\left(\mathrm{C}_{3} \mathrm{~F}_{8}\right)$ gas. Patients were encouraged to maintain a prone posture for two weeks postoperatively.

\section{Outcome measurements and statistical analysis}

Main outcome measures of the study included the median change in BCVA, change in lines of visual improvement, the proportion of eyes with final postoperative BCVA of 20/50 or better, and the mean change in the height of foveal detachment and resolution in myopic foveoschisis as demonstrated by OCT. Statistical analysis was performed using SPSS for Windows version 11.5 (SPSS Inc, Chicago, IL, USA). The mean improvement in BCVA was compared using non-parametric Wilcoxon signed rank test and mean change in the height of foveal detachment was compared using twotailed $t$ test. A p value $<0.05$ was considered statistically significant.

\section{RESULTS}

\section{Patients' demographics}

A total of nine eyes in eight patients were recruited (table 1) The mean (standard deviation (SD)) age of the patients was 53.9 (SD 8.9) years (range 40-65 years). There were six (75\%) females and two (25\%) males. The mean spherical equivalent refractive error was -15.8 (SD 4.5) D (range $-7.0 \mathrm{D}$ to $-25.0 \mathrm{D}$ ) and the mean axial length was 29.0 (SD 1.8) $\mathrm{mm}$ (range $26.3 \mathrm{~mm}$ to $32.1 \mathrm{~mm}$ ). The mean duration of symptoms described by the patient was 8.9 months (range 3-30 months). Preoperative symptoms included blurring of vision in five eyes, metamorphopsia in three eyes, and both blurring of vision and metamorphopsia in one eye. The mean follow up duration after surgery was 17.2 months (range 6-30 months). Seven $(77.8 \%)$ of the nine eyes were phakic
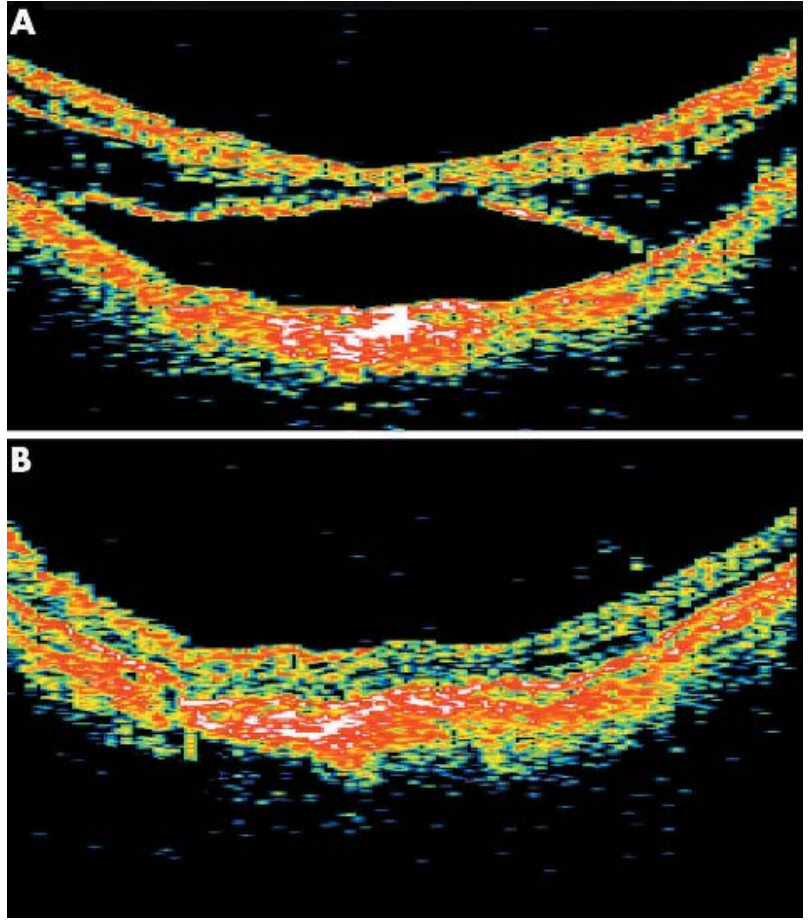

Figure 1 Optical coherence tomography of case 2. (A) Preoperative horizontal OCT scan of the macula revealed extensive retinoschisis with foveal detachment. (B) Six months after vitrectomy, there was complete reattachment of the fovea and resolution of the macular retinoschisis.

before surgery with two (22.2\%) eyes being pseudophakic. The median preoperative BCVA was 20/80 (range 20/50 to 20/400).

\section{Intraoperative data}

Pars plana vitrectomy combined with phacoemulsification and implantation of intraocular lens (IOL) was performed in five $(55.6 \%)$ eyes. Intraoperatively, two cases required surgical induction of PVD by active aspiration as only a partial PVD was found (cases 3 and 9). A premacular epiretinal membrane was found and removed in six $(66.7 \%)$ eyes (cases 1A, 3, 4, 5, 7, and 9). There was one case of intraoperative complication caused by zonular dehiscence during phacoemulsification and a capsular tension ring was inserted to assist the phacoemulsification and IOL implantation.

\section{Visual and anatomical outcomes}

Postoperatively, eight $(88.9 \%)$ of the nine eyes had improvement in BCVA at the last follow up and all patients had

Table 1 Details of nine eyes in eight patients underwent vitrectomy without ILM peeling for myopic foveoschisis

\begin{tabular}{|c|c|c|c|c|c|c|c|c|c|c|c|}
\hline Case & Sex/age/eye & $\begin{array}{l}\text { Follow up } \\
\text { (months) }\end{array}$ & $\begin{array}{l}\text { Refractive } \\
\text { errors (D) }\end{array}$ & $\begin{array}{l}\text { Axial } \\
\text { length } \\
\text { (mm) }\end{array}$ & $\begin{array}{l}\text { Preop lens } \\
\text { status }\end{array}$ & $\begin{array}{l}\text { Combined } \\
\text { Phaco + IOL }\end{array}$ & $\begin{array}{l}\text { Duration of } \\
\text { symptoms } \\
\text { (months) }\end{array}$ & $\begin{array}{l}\text { Preop } \\
\text { visual } \\
\text { acuity }\end{array}$ & $\begin{array}{l}\text { Postop } \\
\text { visual } \\
\text { acuity }\end{array}$ & $\begin{array}{l}\text { Preop foveal } \\
\text { detachment } \\
\text { thickness }(\mu \mathrm{m})\end{array}$ & $\begin{array}{l}\text { Postop foveal } \\
\text { detachment } \\
\text { thickness }(\mu \mathrm{m})\end{array}$ \\
\hline $1 \mathrm{~A}$ & $\mathrm{~F} / 47 / \mathrm{L}$ & 30 & -16.0 & 28.7 & Phakic & Yes & 3 & $20 / 70$ & $20 / 40$ & 287 & 0 \\
\hline $1 \mathrm{~B}$ & $F / 47 / R$ & 20 & -15.0 & 28.7 & Phakic & Yes & 3 & $20 / 70$ & $20 / 40$ & 255 & 0 \\
\hline 2 & $\mathrm{~F} / 48 / \mathrm{L}$ & 26 & -17.0 & 29.0 & Phakic & No & 30 & $20 / 80$ & $20 / 60$ & 592 & 0 \\
\hline 3 & $F / 60 / R$ & 25 & -7.0 & 26.3 & Phakic & Yes & 3 & $20 / 50$ & $20 / 40$ & 497 & 0 \\
\hline 4 & $\mathrm{~F} / 64 / \mathrm{L}$ & 24 & -16.0 & 28.8 & $\mathrm{PClOL}$ & $\mathrm{N} / \mathrm{A}$ & 12 & $20 / 70$ & $20 / 70$ & 270 & 147 \\
\hline 5 & $\mathrm{~F} / 53 / \mathrm{L}$ & 9 & -14.75 & 29.4 & Phakic & Yes & 9 & $20 / 200$ & $20 / 50$ & 937 & 0 \\
\hline 6 & $\mathrm{M} / 50 / \mathrm{L}$ & 8 & -16.0 & 31.1 & $\mathrm{PCIOL}$ & $\mathrm{N} / \mathrm{A}$ & 4 & $20 / 150$ & $20 / 70$ & 863 & 0 \\
\hline 7 & $\mathrm{~F} / 40 / \mathrm{L}$ & 7 & -25.0 & 32.1 & Phakic & No & 7 & $20 / 400$ & $20 / 50$ & 457 & 45 \\
\hline 8 & $M / 65 / R$ & 6 & -15.0 & 26.7 & Phakic & Yes & 9 & $20 / 200$ & $20 / 30$ & 390 & 0 \\
\hline
\end{tabular}



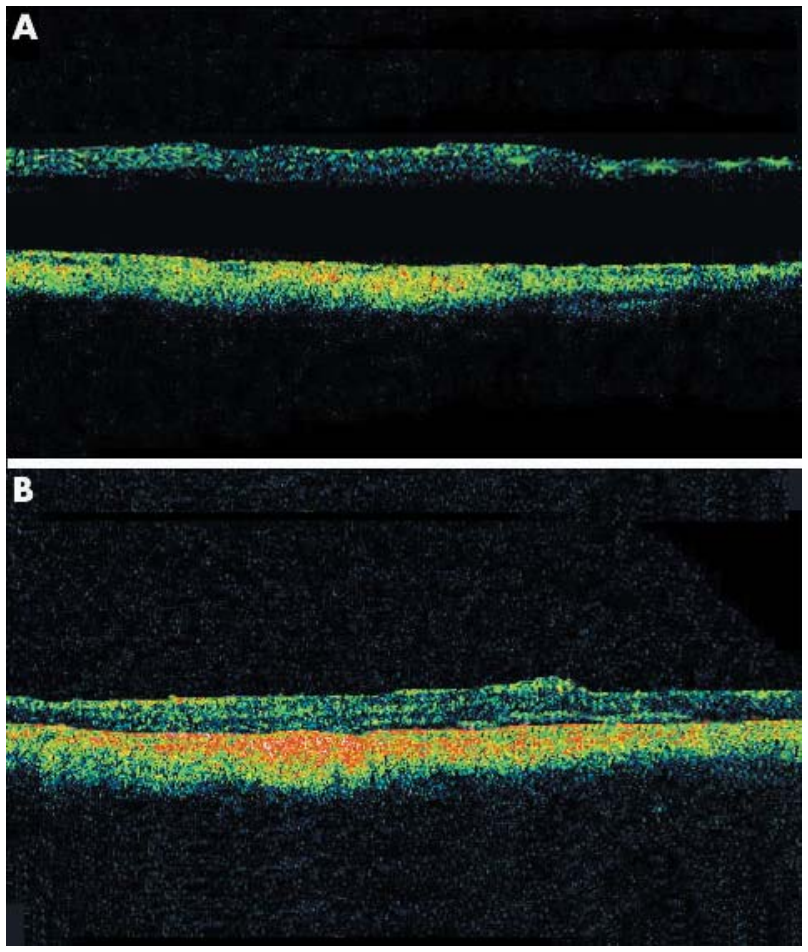

Figure 2 Optical coherence tomography of case 6. (A) Preoperative horizontal OCT scan of the macula revealed foveal detachment without the presence of a macular hole. (B) Six months after surgery, there was complete foveal attachment with resolution of the macular retinoschisis.

symptomatic improvement in visual symptoms after the operation. The median postoperative BCVA at the last follow up was 20/50 (range 20/30 to 20/70). There was significant improvement in the median final BCVA compared with the median preoperative BCVA (Wilcoxon signed rank test, $\mathrm{p}=0.012)$. The mean improvement in BCVA was 3.6 lines (range 0-9 lines). Six $(66.7 \%)$ of the nine eyes had a final BCVA of $20 / 50$ or better, compared with only one ( $11.1 \%$ ) eye preoperatively.

Postoperative OCT showed complete resolution of the myopic foveoschisis in seven $(77.8 \%)$ of the nine eyes after surgery (figs 1 and 2). The remaining two cases had partial resolution of the myopic foveoschisis with reduction in the height of the foveal detachment (fig 3). The mean height of foveal detachment decreased from $505 \mu \mathrm{m}$ preoperatively to $21 \mu \mathrm{m}$ postoperatively (two-tailed $t$ test, $\mathrm{p}<0.001$ ).

\section{Postoperative complications}

One patient (case 6) developed retinal detachment without macular involvement that occurred six weeks after vitrectomy. The patient was treated with scleral buckling with cryotherapy and gas injection. The retina was flat postoperatively and the final BCVA was 20/70. The patient (case 4) with intraoperative zonulysis during phacoemulsification developed gradual decentration of IOL despite intraoperative insertion of capsular tension ring. Reposition of IOL was performed 9 months after vitrectomy and resulted in improved IOL centration. There was no change in the final BCVA compared with preoperative BCVA due to residual myopic foveoschisis with foveal detachment. Another patient (case 4) also developed visually significant cataract 18 months after surgery and her visual acuity deteriorated from $20 / 60$ to $20 / 100$. Cataract surgery was performed and her BCVA improved to $20 / 60$.
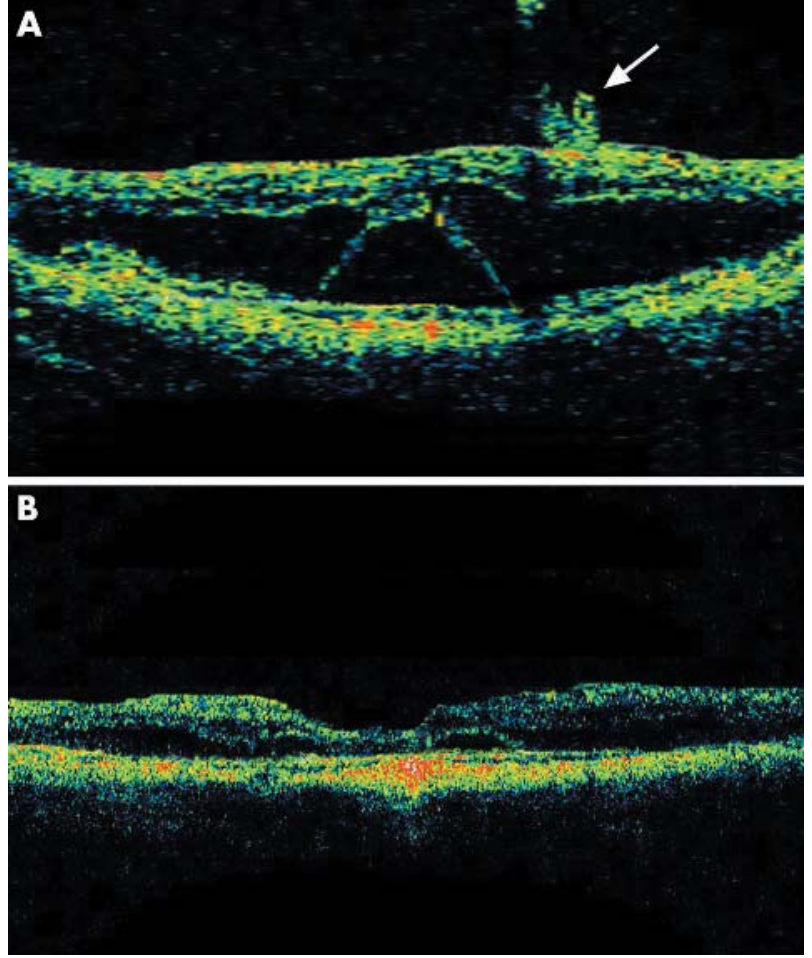

Figure 3 Optical coherence tomography of case 7. (A) Preoperative horizontal OCT scan of the macula demonstrated extensive macular retinoschisis with foveal retinal detachment. Incomplete partial PVD can also be seen in the parafoveal region (arrow). (B) Six months after surgery, there was partial resolution of the macular retinoschisis with reduction in the height of the foveal detachment.

\section{DISCUSSION}

The pathogenesis of myopic foveoschisis is poorly understood and traction caused by premacular vitreous cortex has been postulated to contribute to its development. ${ }^{2}$ Another proposed factor is the posterior ectasia associated with posterior staphyloma in high myopia, resulting in a "stretch retinoschisis". ${ }^{16}$ A degenerative process involving the posterior retina may be another factor associated with myopic foveoschisis as a previous study has shown posterior pole microcystoid degeneration in myopic patients with foveoschisis using OCT. ${ }^{6}$

The level of visual impairment in patients with myopic foveoschisis is variable and vitrectomy with ILM peeling and gas tamponade has been demonstrated to be useful in treating symptomatic cases. ${ }^{2-9}$ Kanda and coworkers reported both anatomical and visual improvements after vitrectomy with ILM peeling and gas tamponade in two highly myopic eyes with myopic foveoschisis. ${ }^{8}$ Kobayashi and Kishi carried out a prospective study to evaluate the use of vitrectomy with ILM peeling in nine eyes of seven patients with myopic foveoschisis. ${ }^{9}$ Foveal reattachment was achieved in eight $(88.9 \%)$ of the nine eyes after surgery; one eye developed a microhole at the macula during brushing of the retinal surface with a silicone tipped cannula for removal of premacular vitreous cortex. All eyes had visual improvement postoperatively. In another study conducted by Ikuno and associates, ${ }^{2}$ vitrectomy with ILM peeling was performed in six eyes with myopic foveoschisis. Five (83.3\%) eyes had complete resolution of the myopic foveoschisis and one eye had partial resolution. Although there was a lack of complete foveal reattachment in all cases, all cases had visual improvement postoperatively. Despite results from these studies, it remained unclear whether ILM peeling was 
necessary for treating myopic foveoschisis and the ideal surgical approach remained speculative. ${ }^{2}$

The rationale of ILM removal in epiretinal membrane surgery is to ensure complete removal of any residual microscopic epiretinal membrane that may be present on the ILM in order to minimise epiretinal membrane recurrence. ${ }^{20}$ Likewise, in patients with myopic foveoschisis, the aim of ILM peeling is to obtain complete relief of macular traction by complete removal of the premacular membrane and vitreous cortex that may reside on the ILM. ${ }^{29}$ Another reason to peel the ILM is due to its rigidity and ILM removal may allow the retina to conform better to the posterior staphyloma. ${ }^{10}$ ILM peeling may also help to remove the collagen fibre and cellular components that may be present in ILM in eyes with myopic foveoschisis. ${ }^{14}$ However, ILM peeling may be technically more difficult in patients with myopic foveoschisis as a result of the associated retinal thinning at the macula. This may predispose complications like iatrogenic macular hole to occur due to surgical trauma. It would therefore be useful to determine whether pars plana vitrectomy without ILM peeling followed by gas tamponade could result in similar success compared with ILM removal.

In our study, seven $(77.8 \%)$ of the nine eyes had complete resolution of the myopic foveoschisis and resulted in visual improvement postoperatively. Benhamou and coworkers have previously described the outcome of pars plana vitrectomy without ILM peeling in three eyes with myopic foveoschisis associated with vitreous traction. ${ }^{6}$ The thickness of the retinoschisis and visual acuity remained the same after the operations and one eye developed a macular hole shortly after vitrectomy. It appeared that gas tamponade was not used in their patients. In our study, with the use of gas tamponade, we achieved similar anatomical and visual results compared with previous studies in which vitrectomy and ILM peeling was performed for myopic foveoschisis. Our results suggest that without ILM peeling, vitrectomy alone followed by gas tamponade may be useful for treating symptomatic patients with myopic foveoschisis.

There are several limitations in our study. Firstly, only a small number of patients were included and a longer period of follow up with more cases will be beneficial in demonstrating the long term recurrence rate of myopic foveoschisis in these patients. Secondly, histological analysis was not performed on the removed epiretinal membrane specimens and it remained uncertain whether small pieces of ILM were actually removed inadvertently in small areas together with the premacular epiretinal membrane. Another limitation was that not all patients uniformly received combined cataract and vitreoretinal surgery. In more than $50 \%$ of eyes, concurrent cataract surgery was performed together with vitrectomy. None of these patients had visually significant cataract and cataract surgery was carried out to avoid subsequent lens surgery.

In summary, vitrectomy and gas tamponade without ILM peeling appears to have favourable visual and anatomical outcomes for treating myopic foveoschisis in highly myopic eyes with posterior staphyloma. Further prospective controlled studies in the future will be useful in demonstrating the effects of ILM peeling compared with no ILM peeling on the outcome of vitrectomy for myopic foveoschisis.

\section{Authors' affiliations}

A K H Kwok, Department of Ophthalmology, Hong Kong Sanatorium and Hospital, Hong Kong, People's Republic of China

A K H Kwok, Clinical Trials Centre, Faculty of Medicine, The University of Hong Kong, Queen Mary Hospital, Hong Kong, People's Republic of China

T Y Y Lai, W W K Yip, Department of Ophthalmology \& Visual Sciences, The Chinese University of Hong Kong, Hong Kong Eye Hospital, Hong Kong, People's Republic of China

\section{REFERENCES}

1 Takano M, Kishi S. Foveal retinoschisis and retinal detachment in severely myopic eyes with posterior staphyloma. Am J Ophthalmol 1999;128:472-6.

2 Ikuno Y, Sayanagi K, Ohii M, et al. Vitrectomy and internal limiting membrane peeling for myopic foveoschisis. Am J Ophthalmol 2004; 137:719-24.

3 Baba T, Ohno-Matsui K, Futagami S, et al. Prevalence and characteristics of foveal retinal detachment without macular hole in high myopia. Am J Ophthalmol 2003;135:338-42.

4 Panozzo G, Mercanti A. Optical coherence tomography findings in myopic traction maculopathy. Arch Ophthalmol 2004;122:1455-60.

5 Akiba J, Konno S, Sato E, et al. Retinal detachment and retinoschisis detected by optical coherence tomography in a myopic eye with a macular hole. Ophthalmic Surg Lasers 2000;31:240-2.

6 Benhamou N, Massin P, Haouchine B, et al. Macular retinoschisis in highly myopic eyes. Am J Ophthalmol 2002;133:794-800.

7 Ishikawa F, Ogino N, Okita K, et al. Vitrectomy for macular detachment without macular hole in highly myopic eyes. Atarashii Ganka $2001 ; 18: 953-6$.

8 Kanda S, Uemura A, Sakamoto Y, et al. Vitrectomy with internal limiting membrane peeling for macular retinoschisis and retinal detachment without macular hole in highly myopic eyes. Am J Ophthalmol 2003; 136:177-80.

9 Kobayashi H, Kishi S. Vitreous surgery for highly myopic eyes with foveal detachment and retinoschisis. Ophthalmology 2003;110:1702-7.

10 Kuhn F. Internal limiting membrane removal for macular detachment in highly myopic eyes. Am J Ophthalmol 2003; 135:547-9.

11 Brooks HL Jr. Macular hole surgery with and without internal limiting membrane peeling. Ophthalmology 2000;107:1939-49.

12 Kwok AK, Lai TY, Man-Chan W, et al. Indocyanine green staining and removal of retinal internal limiting membrane in stage 3 or 4 macular hole surgery. Br J Ophthalmol 2003;87:71-4.

13 Kwok AK, Lai TY. Internal limiting membrane removal in macular hole surgery of severely myopic eyes: a case-control study. $\mathrm{Br} J$ Ophthalmol 2003;87:885-9.

14 Bando H, Ikuno Y, Choi J, et al. Ultrastructure of internal limiting membrane in myopic foveoschisis. Am J Ophthalmol 2005;139:197-9.

15 Haritoglou C, Gandorfer A, Gass CA, et al. The effect of indocyanine-green on functional outcome of macular pucker surgery. Am J Ophthalmol 2003; 135:328-37.

16 Gandorfer A, Haritoglou C, Gandorfer A, et al. Retinal damage from indocyanine green in experimental macular surgery. Invest Ophthalmol Vis Sci 2003;44:316-23.

17 Kwok AK, Yeung CK, Lai TY, et al. The effects of trypan blue on cell viability and gene expression in human retinal pigment epithelial cells. Br J Ophthalmol 2004;88:1590-4.

18 Kwok AK, Lai TY, Yeung CK, et al. The effects of indocyanine green and endoillumination on rabbit retina: an electroretinographic and histologic study. Br J Ophthalmol 2005;89:897-900.

19 Holladay JT. Proper method for calculating average visual acuity. J Refract Surg 1997; 13:388-91.

20 Kwok AK, Lai TY, Li WW, et al. Indocyanine green-assisted internal limiting membrane removal in epiretinal membrane surgery: a clinical and histologic study. Am J Ophthalmol 2004;138:194-9. 